\title{
Knowledge management awareness in South African provincial government departments: The case of KwaZulu-Natal Department of Public Works, Pietermaritzburg
}

\begin{tabular}{|c|c|}
\hline \multicolumn{2}{|c|}{$\begin{array}{l}\text { Authors: } \\
\text { Fulufhelo Nenungwi }{ }^{1} \text { (D) } \\
\text { Francis Garaba }{ }^{1} \text { (D) }\end{array}$} \\
\hline \multicolumn{2}{|c|}{$\begin{array}{l}\text { Affiliations: } \\
\text { 1Department of Information } \\
\text { Studies, Faculty of Social } \\
\text { Sciences, University of } \\
\text { KwaZulu-Natal, } \\
\text { Pietermaritzburg, } \\
\text { South Africa }\end{array}$} \\
\hline \multicolumn{2}{|c|}{$\begin{array}{l}\text { Corresponding author: } \\
\text { Fulufhelo Nenungwi, } \\
\text { fulu.nenungwi@gmail.com }\end{array}$} \\
\hline \multicolumn{2}{|c|}{$\begin{array}{l}\text { Dates: } \\
\text { Received: } 31 \text { Aug. } 2021 \\
\text { Accepted: } 29 \text { Oct. } 2021 \\
\text { Published: } 17 \text { Jan. } 2022\end{array}$} \\
\hline \multicolumn{2}{|c|}{$\begin{array}{l}\text { How to cite this article: } \\
\text { Nenungwi, F. \& Garaba, F., } \\
\text { 2022, 'Knowledge } \\
\text { management awareness in } \\
\text { South African provincial } \\
\text { government departments: } \\
\text { The case of KwaZulu- } \\
\text { Natal Department of Public } \\
\text { Works, Pietermaritzburg', } \\
\text { South African Journal } \\
\text { of Information } \\
\text { Management 24(1), a1456. } \\
\text { https://doi.org/10.4102/ } \\
\text { sajim.v24i1.1456 }\end{array}$} \\
\hline \multicolumn{2}{|c|}{$\begin{array}{l}\text { Copyright: } \\
\text { (C) 2022. The Authors. } \\
\text { Licensee: AOSIS. This wo } \\
\text { is licensed under the } \\
\text { Creative Commons } \\
\text { Attribution License. }\end{array}$} \\
\hline \multicolumn{2}{|l|}{ Read online: } \\
\hline 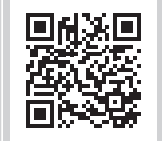 & $\begin{array}{l}\text { Scan this QR } \\
\text { code with your } \\
\text { smart phone or } \\
\text { mobile device } \\
\text { to read online. }\end{array}$ \\
\hline
\end{tabular}

Background: Knowledge management (KM) holds a major influence on the effective delivery of services in government departments as it is tactically affiliated to the formation, composition, and sharing of information to prevent 'reinvention of the wheel' by staffs when performing their jobs. However, few government departments within the South African context have implemented formal KM initiatives.

Objectives: This research sought to examine the KwaZulu-Natal Department of Public Works (Pietermaritzburg) employees' awareness of any KM initiatives, their benefits, and barriers that are preventing the successful implementation of a formal initiative.

Method: A survey research approach was utilised in which structured questionnaires were administered to respondents. Data were analysed using the Statistical Package for the Social Science (SPSS).

Results: The research established that KM initiatives are being practiced informally within the Department and there is a reasonably high level of awareness of these initiatives together with the benefits associated with them. The lack of a dedicated unit for KM and KM professionals are some of the barriers to the successful implementation of formal initiatives.

Conclusion: The research concluded that the Department is in dire need of a formal KM initiative to reap the potential benefits and improve service delivery.

Keywords: public sector organisations; knowledge management implementation; KM; knowledge management awareness; KwaZulu-Natal Department of Public Works; South African provincial government departments.

\section{Introduction}

The impact that the global economy has on organisations today is realised in the modifications they need to continuously make to the way they operate; the organisations need to have endless phases of transformation for them to be seen as effective. Biswas, Khan and Biswas (2017:66) noted that 'public sector organizations (PSOs) are lagging in the implementation of $\mathrm{KM}^{\prime}$ '. There is a need to mainstream knowledge management (KM) across the PSOs to ensure that important knowledge, information and skills are maintained at all times to improve service delivery (Nxesi 2015:80). The working definition for KM in this study is that provided by Bartlett (2021) who noted that:

$\mathrm{KM}$ involves the process of collecting, consolidating, storing, and exploiting knowledge held within an organization, particularly knowledge known to individuals (tacit knowledge), as well as the general store of known knowledge (explicit knowledge). (p. 5)

The PSOs are unable to adapt to the rapidly changing society surrounding them because they are not yet making the required paradigm shift brought about by the information revolution (Minnaar \& Bekker 2005). Within this paradigm, a resource such as information is imperative for effective management so that organisations can efficiently satisfy and deliver the expected level of service (Minnaar \& Bekker 2005). 'PSOs have to embrace new standards that place the management of intangible resources like information at the core of their strategies' (McEvoy, Ragab \& Arisha 2017:37). In the current global economy, 'information is highly important and most businesses are realizing that it can lead to competitive advantage' (Ehlers \& Lazenby 2010:16; Semertzaki 2018:574-575). Unlike the private sector with profit as its clear motive, the over-arching 
aim of PSOs is to add value through service delivery that maximises resource allocation.

Even though the concept of competitive advantage is traditionally associated with the private sector, PSOs should likewise focus on mobilising service delivery and improving organisational performance by considering the importance of knowledge and its management (Gaffoor 2008; Minnaar \& Bekker 2005):

PSOs are now expected to improve their performance to respond to challenges that come with the new knowledge economy by transforming their structures, processes, procedures, and culture of job performance for efficient service delivery. (Betchoo 2016:109)

This could be accomplished by executing KM initiatives that have been effectively used all over the globe in various organisational sectors. Knowledge management initiatives are the approaches used within an organisation 'by which employees, groups, and structural sections work together to generate, preserve, distribute, and successfully utilize information' (Tubigi \& Alshawi 2012:749). Traunmüller (2012) emphasised that if KM can be implemented in PSOs:

[I]t could enhance numerous managerial activities due to its broad scope, for example, constructing an organizational knowledge warehouse which helps to support managers make decisions faster and that can be used as back up during the planning process. (p. 2)

The findings of a survey by the Organisation for Economic Co-operation and Development (OECD) in 2003 highlight the factors that motivate the need to implement a formal KM initiative in the public sector. Such factors include: diminishing the duplication of effort between sections and directorates, improving working relationships and trust within a department, promoting a learning organisation, and sharing knowledge with other departments (OECD 2003:19). 'KM must occupy a central space in the public service if this sector is to seek effective and continually improving service delivery' (Department of Public Service and Administration [DPSA] Framework 2007-2008). According to Hourigan (2017), the aim of implementing KM is to introduce modes of reusing knowledge to improve coordination across PSOs to improve service delivery as they have large quantities of information. However, if these are not properly managed, 'it may prove difficult to link available knowledge to improved service delivery to the citizens' (Maude \& Ncume 2012:580).

This study was conducted in a PSO, namely, the KwaZulu-Natal Department of Public Works (KZN DPW), Pietermaritzburg in the KZN Provincial Government. The Department offers 'wide-ranging construction infrastructure facilities to the various provincial government departments (PGDs)'.

This study addressed the following research questions:

1. What is the level of awareness of KM at the KZN DPW, Pietermaritzburg?

2. What KM initiatives are being applied within the Department and what are their benefits?
3. What are the barriers preventing the successful implementation of a formal KM initiative?

\section{Review of related literature}

Knowledge management is centred on the principle that, just as people are incapable of utilizing their entire mental abilities, organizations are commonly not able to apply completely the information that they have' (King 2009:3). Therefore, KM initiatives are there to fill that gap. The application of KM initiatives within PSOs enhances their effectiveness in delivering services, boosts productivity, and increases the quality of services (Hourigan 2017; Talisayon 2013). Al-Khouri (2014:31) and Colnar and Dimovski (2017:145) attested to this by stating that KM initiatives provide PSOs with the strength to build knowledge to improve productivity and performance. Badimo and Buckley (2014:3449) found that KM initiatives are important and helpful to 'all measures of organizational performance and service delivery'.

An insight into KM initiatives globally, their application within the South African context, empirical studies on KM, and awareness of KM in PSOs now follows.

\section{Knowledge management initiatives globally}

Globally, KM initiatives and the benefits reaped by formally implementing such initiatives in PSOs are an issue that is in its initial stage or under-researched (Naghavi, Dastaviz \& Nezakati 2013). There is a scarcity of research that provides evidence as to why KM initiatives should be implemented in PSOs (McEvoy, Arisha \& Ragab 2015:4). Moreover, there is a deficiency in the understanding of $\mathrm{KM}$ and inadequate awareness regarding its benefits (Cong, Li-Hua \& Stonehouse 2007:258)

\section{Use of knowledge management in South African public sectors}

Within the South African context, it is evident that KM is being used in municipalities and government departments for various reasons. For example, to raise the levels of service delivery by encouraging a culture of learning amongst employees; translating individual knowledge into corporate intellectual capital; and to improve the management and accessibility of corporate information assets for specialised information services (Phalatse 2017; Smith 2017; Western Cape Provincial Government 2013).

\section{Empirical studies on knowledge management initiatives in the public sector}

Empirical studies on KM initiatives in PSOs within the African context include Kimani (2013), Mphahlele (2010), Ncoyini and Cilliers (2016), Ondari-Okemwa (2007), Potgieter, Dube and Rensleigh (2013) and Ramohlale (2014), which showed that although there are no formal structures for managing knowledge in these organisations, a large amount of knowledge flows through them and KM is barely 
understood in some organisations. However, some organisations regarded $\mathrm{KM}$ as important as it has been present for over a decade in the country like South Africa, and several national departments are at various stages of putting KM into practice. The importance of getting support from top management for successful KM initiatives was recommended and the lack of awareness and commitment were seen as barriers to KM success.

\section{Awareness of knowledge management initiatives in public sector organizations}

With regards to KM awareness in PSOs, research by Cong and Pandya (2003), Khanal (2016), Ling, Bakar and Islam (2014) and Valaei and Aziz (2012) found that the level of awareness for KM in PSOs is on a medium level as it is not new, as some of the organisations knowingly or unknowingly practiced it. Their investigations also revealed challenges and barriers for successful implementation of KM initiatives such as the lack of understanding of KM and its benefits.

The literature above attests to a knowledge gap regarding the awareness amongst PSOs' employees in South Africa regarding KM initiatives and the benefits of these initiatives. The empirical study on which this article is based sought to address this gap.

\section{Conceptual framework}

The Knowledge Conversion Model, conceptualised by Nonaka and Takeuchi in 1995, informed the theoretical foundation and orientation of the study. The model is one of the models within the knowledge category of KM. Other models include: Boisot's Knowledge Category Model (1987) and Hedlund and Nonaka's Knowledge Management Model (1993). The Model of Knowledge Conversion was preferred as it focused on the interrelations amongst individual and organisational knowledge within organisations and has been utilised in associated areas of KM (Karuoya \& Senaji 2017; Memon 2015; Nonaka, Reinmoeller \& Senoo 2000).

This knowledge conversion model presents organisations with four modes through which knowledge is transformed when individual and organisational knowledge interrelate (Nonaka \& Takeuchi 1995:62). The modes are referred to as: socialisation, externalisation, combination, and internalisation (SECI). The combination of these modes aims to keep the organisational knowledge updated and aligned to improve effective service delivery (Pata 2010).

A thorough understanding of $\mathrm{KM}$ theories regarding the creation and sharing of knowledge was needed to help the authors analyse the awareness of KM initiatives at the KZN DPW. Building on this, the study regarded the influence of the dynamic process of knowledge conversion on organisational efficiency relevant towards service delivery. This Model works in conjunction with $\mathrm{KM}$ initiatives as it is focused on how organisational knowledge is created, captured, shared, and converted from one form of knowledge to another and, in addition, the Model generally deals with how organisations can manage their knowledge. The spectrum of knowledge formed between tacit and explicit knowledge, and the three-tier (individual, group, organisation) approach of knowledge sharing and dissemination is important as it increases organisational productivity (Dalkir 2005:52).

The Knowledge Conversion Model presents the transfer of knowledge as a continuous learning process or recreation of knowledge as it moves between tacit and explicit knowledge (Bartlett 2021:55). Thus, when the knowledge creation process is conducted effectively, employees gain from the repeated improvements of the organisational knowledge, often within short periods (Wiig 1993:217). Organisational learning is thus deepened as knowledge is translated and transformed through a spiral of conversions (Bartlett 2021:55).

\section{Research methodology}

The survey research method was used to conduct this study. The targeted population consisted of 77 employees (out of 325) from four sections of the KZN DPW Head Office. These sections included, Strategic Management (SM), Human Resources (HR), Information Technology (IT), and Monitoring and Evaluation (M\&E). Even though a KM initiative requires commitment and determination from all organisational members, purposive sampling on these sections was necessary because they are arguably more significant to the operation of the Department. In addition, these sections are most likely to be involved with the technical and planning aspects for the implementation of a formal KM initiative. Gay and Airasian (2003:113) advised that for a population with less than 100 people, a census is considered appropriate. With the census method, there may be a higher degree of accuracy in the data gathered since the whole population is included (Farooq 2013), which may result in a greater degree of representativity of the collected data (Babbie 1998).

A self-administered questionnaire was used to investigate the attitudes and opinions of the KZN DPW employees regarding the KM initiatives within the Department. The questionnaire was designed to gather quantitative data and consisted of closed multiple-choice questions only. Responses were analysed using the Statistical Package for the Social Science (SPSS version 21.0 [2012] was used) software and findings are presented in tabular and graphic form.

The authors adhered to the ethical requirements of the University of KZN (Humanities and Social Sciences Research Ethics Committee) Research Ethics Policy (UKZN 2014). In doing so, the data collection instrument clearly explained the purpose of the study through an informed consent cover letter. The respondents were assured of anonymity as their names would not be mentioned when reporting the findings. Respondents were also informed that their participation was voluntary and that they could withdraw from the research project at any stage.

The questionnaires were distributed to the respondents by the authors. Of the 77 employees that were targeted as 
respondents for the study, $61[N=61]$ returned fully completed questionnaires producing a $79 \%$ response rate. This response rate was reached after the authors repeatedly reminded the respondents through email or telephonic communication to complete and return the questionnaires. In most cases, the authors personally collected the returned questionnaires from respondents' offices, while other respondents returned the questionnaire by scanning and emailing it to the authors.

\section{Presentation of results}

The research questions outlined above provide the basis for the presentation of the findings. To begin with, demographic data concerning the respondents are given.

\section{Demographic data}

In terms of gender, $36(59 \%)$ of the respondents indicated female and $25(41 \%)$ male, reflecting the dominance of females within the Department under study. With regard to terms of employment, $52 \quad(85 \%)$ respondents were permanently employed and $9(15 \%)$ were working under contract. The large percentage of permanently employed respondents can be advantageous if a formal $\mathrm{KM}$ initiative was to be implemented as it takes a long process to achieve results and requires commitment. Concerning commitment, employees in the Department can be said to be committed to serving as only $3(5 \%)$ of the respondents had been working in the Department for less than a year, whilst as many as $23(38 \%)$ had been working for more than 10 years. In terms of the sections that the respondents were working under, most of the respondents $42(68 \%)$ were employed in HR, while the section with the smallest representation was SM with only 3 (5\%) respondents (see Figure 1).

\section{Awareness of knowledge management at the KwaZulu-Natal Department of Public Works}

Opinions regarding the basics of KM were solicited from the respondents. Figure 2 indicates the responses of the respondents on whether they had heard about the term KM before participating in the study or not. While a majority of respondents $(37,61 \%)$ had heard about the term, a surprisingly

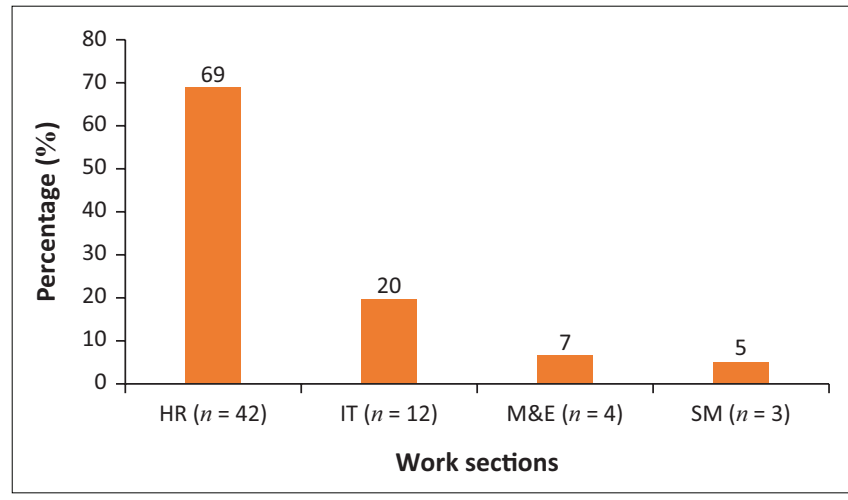

SM, Strategic Management; HR, Human Resources; IT, Information Technology; M\&E, Monitoring and Evaluation.

FIGURE 1: Sections respondents currently working under $(N=61)$. high number $(24,39 \%)$ had never heard about KM. For those who did not know about KM, a definition of the term was provided for them to gain some understanding of the concept, thus enabling them to respond to the subsequent questions.

The 37 respondents who indicated that they knew about KM were asked a follow-up question to determine where they had heard about the concept. Eleven (30\%) of the 37 respondents indicated that they had heard about KM from the KZN DPW, 10 (27\%) mentioned short courses as the source, 2 (5\%) identified other departments, and a further 2 respondents (5\%) mentioned conferences as their source of information. Twelve (33\%) respondents indicated 'Other' and did not specify.

\section{Knowledge management initiatives being applied within the department and their benefits}

Concerning KM initiatives that were already in place within the Department, a multiple response question was posed. Thirty-nine $(64 \%)$ respondents were of the opinion that knowledge sharing was the most used practice. This was followed by the knowledge utilisation practice as indicated by $25(41 \%)$ respondents. The dissemination of knowledge was the third most mentioned practice with 21 (34\%) respondents specifying the same. Knowledge retention and knowledge creation were the least mentioned KM practices used within the Department indicated by $14(23 \%)$ and $13(21 \%)$ respondents, respectively.

Concerning the benefits of implementing a formal KM initiative, respondents were asked whether they thought employees, as well as the Department, would benefit from such an initiative. Figure 3 shows that a substantial majority of respondents $(51,84 \%)$, thought that there are benefits to be attained from a formal KM initiative.

Figure 4 shows the respondents' answers regarding whether implementing a KM initiative in the Department would enhance performance and service delivery. Again, a substantial

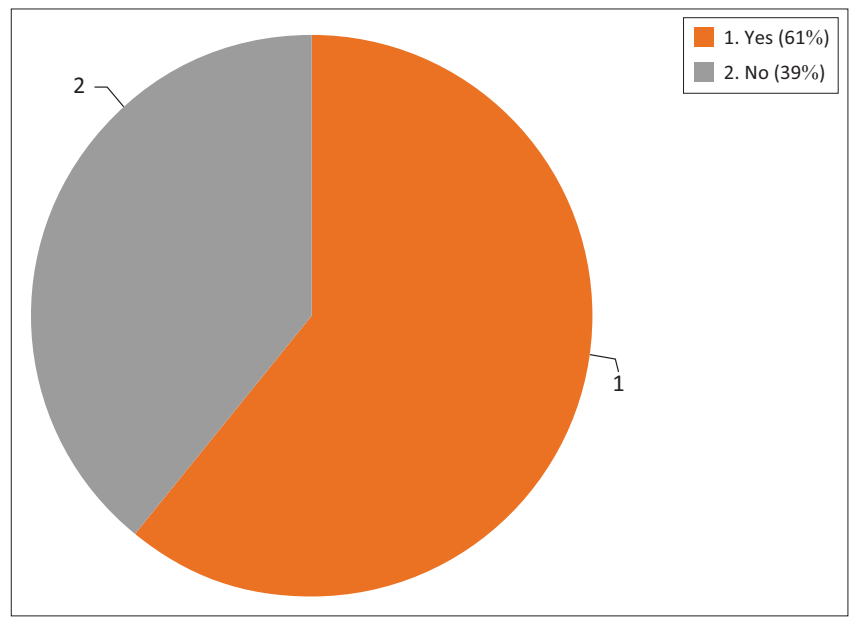

$\mathrm{KM}$, knowledge management.

FIGURE 2: Prior awareness of knowledge management $(N=61)$. 


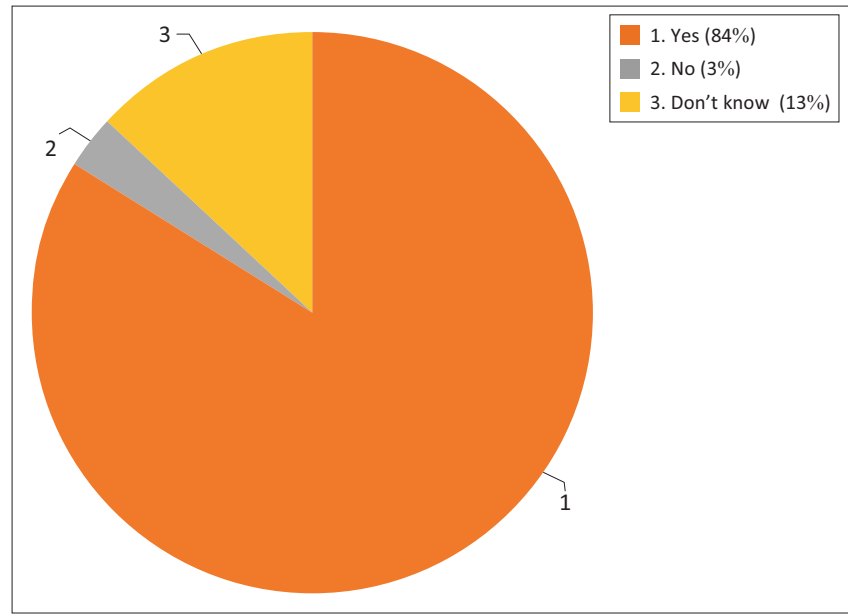

KM, knowledge management.

FIGURE 3: Benefits to employees from a knowledge management initiative $(N=61)$.

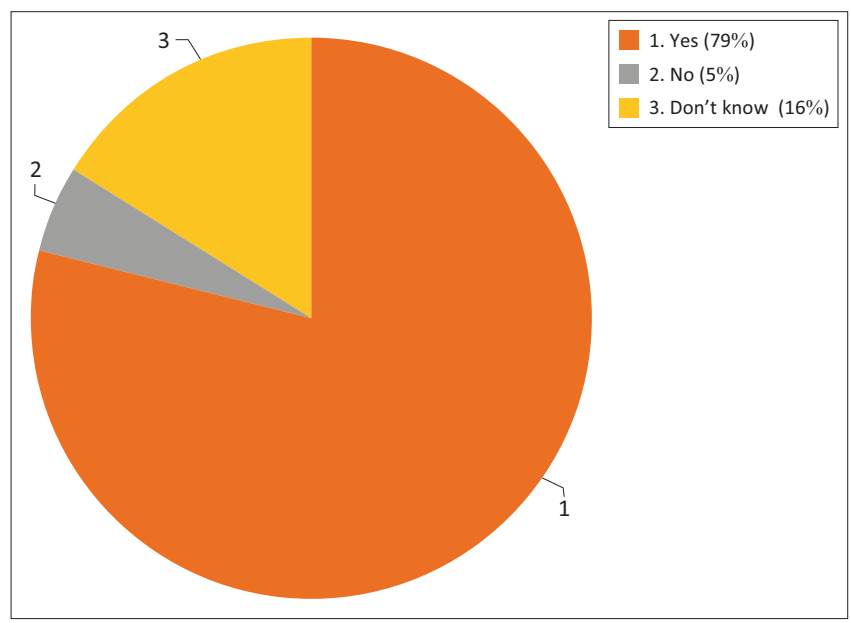

KM, knowledge management.

FIGURE 4: Implementing a knowledge management initiative at KwaZulu-Natal Department of Public Works to enhance performance and service delivery $(N=61)$.

majority of respondents $(48,79 \%)$ believed that a KM initiative, if implemented, would enhance departmental performance and service delivery; 10 (16\%) respondents did not know if KM would help in this regard; and 3 (5\%) respondents stated that KM will not assist the Department.

Respondents were further asked if they would support a KM initiative if implemented within the Department. It can be seen from Figure 5 that of the 61 respondents the vast majority of $56(92 \%)$ indicated that they would support such an initiative if implemented. Of the remaining 5 respondents, $3(5 \%)$ indicated that they would not support such an initiative, while $2(3 \%)$ were undecided in terms of their support or not.

\section{Barriers preventing the successful implementation of a formal knowledge management initiative}

With regard to determining the barriers preventing the implementation of a formal KM initiative at the KZN DPW, a quick analysis of where the Department is when benchmarked against the three important success elements of KM, namely, people, processes and technology was conducted. This quick analysis is referred to as a KM readiness assessment (Mohd Zin \& Egbu 2010:789). A KM readiness assessment is an evaluation of the level of the commitment or the plan to take part in the KM practice by employees within a normal working environment (Jalaldeen, Karim \& Mohamed 2009:302). Shirazi, Mortazavi and Azad (2011:167) stated that for an organisation to develop a KM strategy, it must first evaluate its willingness, which also includes recognising barriers within the organisation that can prevent the adoption of a KM initiative.

Findings regarding the readiness of the KZN DPW to implement a formal KM initiative as displayed in Table 1 indicate that management in the Department does have a 'convincing knowledge management strategy...' as 46 (75\%) respondents attested to this statement, whilst $8(13 \%)$ respondents did not know and 7 (12\%) felt that such a vision does not exist.

Concerning the capturing of knowledge within the Department, 42 (69\%) respondents attested that there are effective processes in place to gather, organise as well as exploit key knowledge. Eleven (18\%) respondents indicated that they did not know about such processes and eight $(13 \%)$ respondents felt that these processes did not exist within the Department.

In terms of storing explicit knowledge within the Department, there was a slight difference between those respondents (26, 43\%) who agreed 'There are regularly maintained knowledge records ... that are readily accessible across the Department' and those respondents $(25,41 \%)$ who indicated that they did not know if this was the case. Ten (16\%) respondents indicated that they did not agree with such records being regularly maintained and readily accessible.

When it comes to the codification of tacit knowledge, a small majority of the respondents $(32,53 \%)$, mentioned that they knew the dominant specialists in the various areas of knowledge inside their section and that there were mechanisms available to systematise personal knowledge into organisational knowledge. Nineteen (31\%) respondents did not know about these experts or the mechanisms in place to transform tacit to explicit knowledge, while 10 $(16 \%)$ respondents indicated that knowledge codification does not take place in their section.

The Department has a culture that encourages the sharing of knowledge amongst employees. This is reflected by the 38 (62\%) respondents who attested to knowledge sharing across departments and informal knowledge exchange being actively encouraged. However, a relatively high percentage $(30 \%)$ of the respondents were of the opposite view, while $5(8 \%)$ respondents indicated that they did not know. 
A substantial minority of respondents $(24,40 \%)$ were of the opinion that a knowledge unit to facilitate the management of knowledge within the KZN DPW did not exist, while 21 $(34 \%)$ did not know. Interestingly, there were 16 (26\%) respondents who attested to the Department having a knowledge unit in place.

In terms of the Department's technical infrastructure that can support formal KM initiatives, a majority of respondents, $41(67 \%)$, indicated that they could find important information using technologies available within the Department. However, 16 (26\%) respondents said that they were unable to

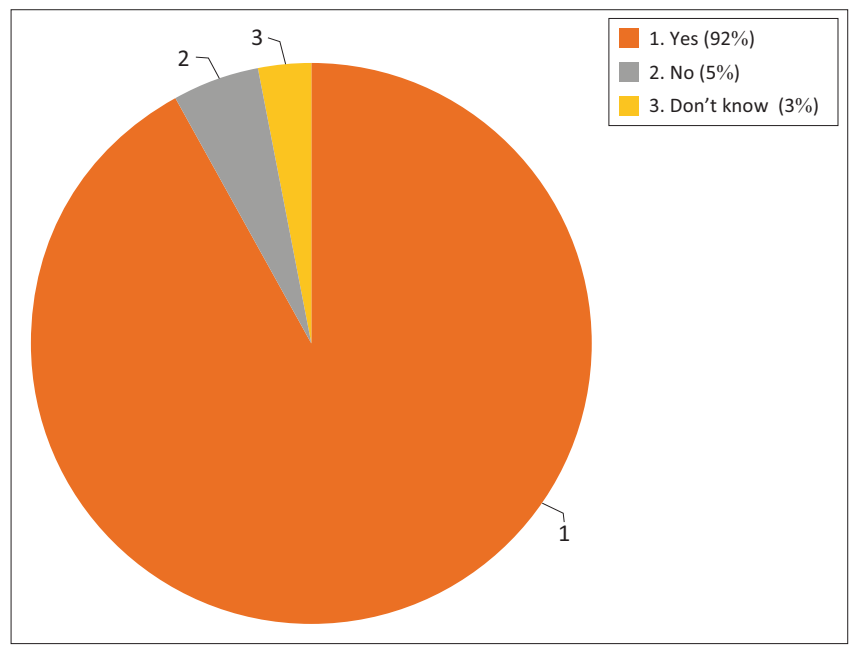

$\mathrm{KM}$, knowledge management.

FIGURE 5: Respondents support for a knowledge management initiative $(N=61)$. do so and $4(7 \%)$ respondents did not know whether they could or not. While, 35 (57\%) respondents indicated that they do not use KM tools to access information, 19 (31\%) respondents indicated that they did use such tools to access information and $7(11 \%)$ respondents did not know. A majority of respondents $(39,64 \%)$ used databases to access information, $15(25 \%)$ respondents did not, and $7(11 \%)$ did not know whether they used databases or not. With regard to using Groupware software, such as email to access information, 42 (69\%) respondents indicated that they did, 12 (20\%) did not and again $7(11 \%)$ did not know. A majority of the respondents $(44,2 \%)$ used bulletin boards or e-departmental notices to access information, 11 (18\%) respondents did not do so and 6 $(10 \%)$ did not know whether such boards or notices were used to access information. Seven (11\%) respondents believed that the Department had a KM officer. A small majority of respondents $(32,52 \%)$ believed that such a position did not exist and $22(36 \%)$ did not know.

With regards to the organisational strategy, respondents were asked to indicate whether the KZN DPW gives priority to 'ensuring that knowledge that is generated is accurate, reliable, and delivered on time...' In response to the question, a small majority of respondents $(32,52 \%)$ stated that the DPW does give priority to such a strategy. However, 14 (23\%) respondents stated that the Department did not give such priority and $15(25 \%)$ indicated that they did not know.

Finally, the research sought to establish the availability of procedures to capture tacit knowledge held by the departing

TABLE 1: Knowledge management readiness assessment $(N=61)$.

\begin{tabular}{|c|c|c|c|}
\hline Variable & Yes & No & Don't know \\
\hline \multicolumn{4}{|l|}{ 1. Leadership: Relates to vision, mission, and values regarding KM } \\
\hline Does your Department have a convincing knowledge management strategy, actively promoted by your top management? & $75 \%$ & $12 \%$ & $13 \%$ \\
\hline \multicolumn{4}{|l|}{ 2. Processes: Relates to capturing of knowledge } \\
\hline Our Department has systematic processes for capturing and protecting key knowledge assets. & $69 \%$ & $13 \%$ & $18 \%$ \\
\hline \multicolumn{4}{|l|}{ 3. Explicit knowledge: Relates to the store of knowledge } \\
\hline $\begin{array}{l}\text { There are regularly maintained knowledge records with structured knowledge and clear ownership of knowledge entities } \\
\text { readily accessible. }\end{array}$ & $43 \%$ & $16 \%$ & $41 \%$ \\
\hline \multicolumn{4}{|l|}{ 4. Tacit knowledge: Relates to the codification of tacit knowledge } \\
\hline $\begin{array}{l}\text { I know the best experts in the different domains of key knowledge within my section and there are mechanisms in place } \\
\text { to codify their tacit knowledge into an explicit format. }\end{array}$ & $53 \%$ & $16 \%$ & $31 \%$ \\
\hline \multicolumn{4}{|l|}{ 5. Culture/structure: Relates to encouragement towards KM } \\
\hline $\begin{array}{l}\text { Is knowledge sharing across departmental boundaries actively encouraged and does your workplace encourage informal } \\
\text { knowledge exchange? }\end{array}$ & $62 \%$ & $30 \%$ & $8 \%$ \\
\hline \multicolumn{4}{|l|}{ 6. Knowledge unit: Relates to facilitation for KM } \\
\hline Is there a KM directorate that coordinates knowledge repositories to support key decision-making? & $26 \%$ & $40 \%$ & $34 \%$ \\
\hline - We can find important information from the intranet. & $67 \%$ & $26 \%$ & $7 \%$ \\
\hline $\begin{array}{l}\text { - We use KM technological tools such as blogs, Facebook, Twitter and mobile phones to access information to access } \\
\text { information. }\end{array}$ & $31 \%$ & $57 \%$ & $12 \%$ \\
\hline - We use databases to access information. & $64 \%$ & $25 \%$ & $11 \%$ \\
\hline - We use Groupware software like email to access information. & $69 \%$ & $20 \%$ & $11 \%$ \\
\hline - We use bulletin boards or e-departmental notices to access information. & $72 \%$ & $18 \%$ & $10 \%$ \\
\hline - We have a KM Officer to manage intellectual capital. & $12 \%$ & $52 \%$ & $36 \%$ \\
\hline \multicolumn{4}{|l|}{ 8. Organisational strategy } \\
\hline Priority is given in ensuring that knowledge that is generated is accurate, reliable, and delivered on time. & $52 \%$ & $23 \%$ & $25 \%$ \\
\hline \multicolumn{4}{|l|}{ 9. Human resources } \\
\hline There are procedures to capture tacit knowledge of employees who are leaving the Department. & $49 \%$ & $20 \%$ & $31 \%$ \\
\hline
\end{tabular}

$\mathrm{KM}$, knowledge management. 
workforce. Less than half of the respondents (30, 49\%) attested to the availability of such procedures in the Department whilst 12 (20\%) respondents believed that these procedures were not in place and 19 (31\%) indicated that they did not know.

\section{Discussion}

As with the presentation of the findings above, the three research questions on which the study was based provide the framework for the discussion.

\section{Awareness of knowledge management within the KwaZulu-Natal Department of Public Works}

It is evident that there is a general understanding and awareness of what $\mathrm{KM}$ comprises amongst the majority $37(61 \%)$ of respondents in the KZN DPW. However, it is also evident that there is a definite need to increase awareness of $\mathrm{KM}$ if a $\mathrm{KM}$ initiative is to be formally implemented given that a fairly substantial percentage $24(39 \%)$ of respondents were 'still in the dark' regarding KM. To bridge this awareness gap, the Department is expected to provide introductory workshops regarding KM initiatives to employees before they can be implemented. These findings corroborate what the study by Dube (2009) emphasised, namely, that it is important to inspect the level of employees' understanding of KM before implementing KM initiatives. Employees having a good awareness and understanding of $\mathrm{KM}$ is important for enabling an organisation to create its own KM initiative suitable to its mission (Valaei \& Aziz 2012).

\section{Knowledge management initiatives being applied within the department and their benefits}

The findings indicate that there are various $\mathrm{KM}$ initiatives within the Department. However, these take place on an informal basis. Knowledge sharing was the most used initiative followed by knowledge utilisation. Sharing knowledge effectively amongst employees without a formal $\mathrm{KM}$ initiative can be very challenging since there is the issue of trust in terms of with whom knowledge is to be shared and what knowledge is to be shared. The lack of a formal KM initiative creates competition amongst employees and, as a result, they may hold back on sharing important knowledge since it may not be clear how the other person will use it. The practice of informal KM initiatives limits the Department from obtaining the potential benefits of the initiatives (see below) as well as active participation from all employees because of the lack of awareness programmes to help employees understand KM. This finding resonates with the study conducted by Nengomasha, Mubuyaeta and BeukesAmiss (2017) who established that the Ministry of Gender Equality and Child Welfare in Namibia had 'no programs put in place to educate and bring awareness to the understanding and the importance of $\mathrm{KM}^{\prime}$. Similarly, Wilson and Nawe (2017) confirmed the lack of such programmes at the Mbeya University of Science and Technology, Tanzania, and this was an inhibiting factor for the successful implementation of KM initiatives.

There is an increasing realisation of the importance of KM in enhancing organisational performance and service delivery within the South African public sectors (Hourigan 2017). It is also noticeable from the results of this research that a majority $48(79 \%)$ of the respondents recognised this importance. In line with this finding, a substantial majority 56 (92\%) of the respondents stated that they would support a formal KM initiative if implemented. This bodes well for the future in that should the Department decide to establish and implement an effective KM initiative, the employees would be open to new approaches and routines.

\section{Barriers preventing the successful implementation of a formal knowledge management initiative}

The findings from the KM readiness assessment revealed some of the barriers that could prevent the successful implementation of a formal KM initiative within the KZN DPW. It is evident from the findings that the Department has the desire in terms of a vision to implement a KM initiative even though this still needs to be accentuated throughout the entire Department. For example, drawing employees' attention towards knowledge capturing processes and how they should be applied across the entire Department.

The finding relating to the storage of explicit knowledge within the Department can be seen as a barrier to the successful implementation of a formal KM initiative. This underscores the importance of the Department ensuring that employees are aware of the platforms that can be useful to them to achieve their daily jobs. The formal implementation of a KM initiative will help the Department, as well as its employees, identify specialists in the various areas of knowledge in the different sections to systematise personal knowledge into organisational knowledge.

Formal KM initiatives require a strong organisational culture that encourages knowledge sharing and consultation (Kermally 2002), and the findings of this study revealed that the culture relating to knowledge sharing across departmental boundaries and informal knowledge exchange in the Department was actively encouraged as indicated by a majority $38(62 \%)$ of the respondents. Nevertheless, when it comes to the organisational culture there is always room for improvement as $18(30 \%)$ of the respondents thought that such a culture did not exist and a further $5(8 \%)$ did not know either way. Bearing in mind that the Department continuously recruits new personnel, it is important that such a culture is continuously emphasised and promoted.

Another barrier identified from the findings of this study is the Department not having a KM unit staffed by a specialist such as a KM officer to, amongst other responsibilities, ensure the provision of information to support key decisionmaking (despite a minority of respondents believing that 
such a unit existed). Having such a unit is important if a formal KM initiative is to be implemented, as a dedicated focus to coordinate the supply of information to sustain imperative decision-making is required. This finding resonates with that of study conducted by Ramohlale (2014:142), who also found that the Department of Defence lacks KM professionals and a component dedicated to managing their intellectual capital.

The study found that a majority 42 (above $60 \%$ ) of respondents believed that they were able to use networks, databases, Groupware software, bulletin boards or e-departmental notices to find and access information using the technologies available within the Department. Rather than a barrier, this finding can be regarded as an enabling factor for the successful implementation of a formal KM initiative as advanced information and communication technology (ICT) skills are critical for fostering and facilitating $\mathrm{KM}$ processes within organisations. It is evident, however, that more could be done within the Department to encourage the use of KM tools.

For a KM initiative to be successful, it should be aligned to the organisational strategy (David 2011; Omotayo 2015). The findings of this study indicate that a small majority of respondents 32 (52\%) believed that in terms of the Department's strategy, priority is given to promoting the creation and preservation of new knowledge and ensuring that it is delivered amongst employees promptly. Given the small majority, it is evident that more could be done in terms of implementing and promoting such a strategy. The lack of a formal KM initiative (which would embrace such a strategy), results in knowledge loss and 'reinventing the wheel' in terms of work processes, hence the importance of implementing such an initiative. Similarly, the HR procedures that are in place to capture the tacit knowledge of the departing workforce will not be as effective if there is no formal KM initiative since there will be no traceable process to prove what is and has been done with the tacit knowledge extracted from those exiting the workforce.

\section{Recommendations}

Various recommendations emerge from the findings and discussion above and these are outlined below:

- The KZN DPW needs to raise awareness of KM and KM initiatives across the entire Department before a formal $\mathrm{KM}$ initiative can be implemented. It is also critical that the employees within the Department should be enlightened about the benefits that can be attained through such an initiative to avoid participation resistance.

- A KM unit equipped with KM professionals and advanced ICT tools should be established within the Department before the implementation of a formal KM initiative.
- The KZN DPW should formally implement a KM initiative that is strategically aligned to the mission and vision of the Department.

- The findings of the study have implications for the KZN DPW and other PGDs in South Africa. There is a need to consider the formal implementation of KM initiatives for more efficient and effective service delivery.

- Finally, this study was conducted in a public institution in the KZN Province and future research could be carried out in other public institutions in both KZN and other provinces. Similar studies could be extended to private organisations to investigate their readiness for the adoption of formal KM initiatives and to compare findings.

\section{Conclusion}

This study was conducted with a special focus on four sections within the KZN DPW Head Office. The assumption here was that what is undertaken at the Head Office can automatically be adopted in the other regional offices. This study provided a demonstration that there is a reasonably high level of awareness of KM and KM initiatives amongst employees in the Department (as presented in Figure 2) as well as the evidence of the informal practice of $\mathrm{KM}$ initiatives.

It should be noted that the effectiveness of a government department lies in the continuous productivity, innovativeness and connectivity of its employees and a formal KM initiative is there to fulfil such purposes (Biswas et al. 2017:66). This requires PSOs to have advanced technology infrastructures to allow workers to disseminate knowledge broadly because, with the requisite ICT support, a KM initiative can be facilitated and enhanced (Hasanali 2002:3; Nazim \& Mukherjee 2016:235-236). Should a formal KM initiative be implemented, it should not be viewed as a new stand-alone management strategy (Shockley 2000:58), but rather as one of the organisation's strategic tools (Omotayo 2015) that needs to be managed as per the organisational strategy (David 2011).

\section{Acknowledgements}

The authors wish to acknowledge the support from the authorities of the University of KwaZulu-Natal, South Africa, and the Provincial Department of KwaZulu-Natal, Pietermaritzburg, South Africa.

\section{Competing interests}

The authors declare that they have no financial or personal relationship(s) which may have inappropriately influenced them in writing this article. The views and opinions expressed in this article are those of the authors and do not necessarily reflect the official policy or position of the institutions. 


\section{Authors' contributions}

F.N. was the research leader and participated in designing the research questions, methodology used, literature review, data collection, codification and analysis, and writing of the manuscript. F.G. contributed in literature review, methodology used, data analysis, and manuscript editing.

\section{Ethical considerations}

The University of KwaZulu-Natal, Humanities and Social Sciences Research Ethics Committee granted the researcher ethical clearance (Reference number: HSS/1202/017M)

\section{Funding information}

This research received no specific grant from any funding agency in the public, commercial, or not-for-profit sectors.

\section{Data availability}

No names will be provided in questionnaires and when reporting, the researcher will refer to participants as respondents.

Feedback to participants will be given by providing a copy of the finished thesis to each section that was involved; moreover, another copy will be handed to the office of the Head of Department which can be accessed by all employees within the Department.

\section{Disclaimer}

The views and opinions expressed in this article are those of the authors and do not necessarily reflect the official policy or position of the institutions.

\section{References}

Al-Khouri, A.M., 2014, 'Fusing knowledge management into public sector corporates excellence culture: A review of the field and the case of the Emirates Identity Authority', Journal of Knowledge Management, Economics and Information Technology 4(3), 1-89.

Babbie, E., 1998, The practice of social research, 8th edn., Wadsworth Publishing Company, Belmont, CA.

Badimo, K.H. \& Buckley, S., 2014, 'Improving knowledge management practices in the South African healthcare system', International Journal of Social, Behavioral, Educational, Economic, Business and Industrial Engineering 8(11), 3449-3458.

Bartlett, J.A., 2021, Knowledge management: A practical guide for librarians, Rowman and Littlefield, Lanham, MD.

Betchoo, N.K., 2016, Public sector management: A millennial insight, Ventus, Frederiksberg, viewed 08 May 2017 from http://bookboon.com/en/public-sectormanagement-ebook.

Biswas, S., Khan, A. \& Biswas, S.K., 2017, 'The prospect of adopting knowledge management in public service organisations: Evidence from a developing country', European Journal of Research and Reflection in Management Sciences 5(3), 51-68.

Boisot, M., 1987, Information and organizations: The manager as anthropologist, Fontana, London.

Colnar, S. \& Dimovski, V., 2017, 'Knowledge management initiatives benefits for the Slovenian public sector', Journal of Contemporary Management Issues 22, 145-161.

Cong, X., Li-Hua, R. \& Stonehouse, G., 2007, 'Knowledge management in the Chinese public sector: An empirical investigation', Journal of Technology Management in China 2(3), 250-263. https://doi.org/10.1108/17468770710825188

Cong, X. \& Pandya, K.V., 2003, 'Issues of knowledge management in the public sector', Electronic Journal of Knowledge Management 1(2), 25-33.

Dalkir, K., 2005, Knowledge management in theory and practice, Elsevier, London.
David, F.R., 2011, Strategic management: Concepts and cases, 13th edn., PrenticeHall, Upper Saddle River, NJ.

Department of Public Service and Administration (DPSA), 2007-2008, Towards a knowledge management framework for the public service, viewed 23 February 2017, from http://www.dpsa.gov.za/dpsa2g/documents/misc/Concept $\% 20$ document $\% 20$ for $\% 20$ NKMF\%20Workshop.pdf.

Dube, O.P.X., 2009, 'Conducting a knowledge audit at the National Department of Housing', Unpublished Dissertation (MIS.), University of KwaZulu-Natal, Information Studies Programme, School of Sociology and Social Studies, viewed 15 January 2017, from http://researchspace.ukzn.ac.za/bitstream/handle/10413/589/Dube OPX_2009_Thesis.pdf?sequence=2\&isAllowed $=y$.

Ehlers, T. \& Lazenby, K., 2010, Strategic management: South African concepts and cases, Van Schaik, Pretoria.

Farooq, U., 2013, What is the census method of data collection, advantages and disadvantages?, viewed 30 August 2017, from http://www.studylecturenotes. $\mathrm{com} /$ social-research-methodology/what-is-census-method-of-data-collectionadvantages-disadvantages.

Gaffoor, S., 2008, 'Assessing readiness for the implementation of knowledge management in local government: The case of Stellenbosch municipality', Unpublished Dissertation (M.C.), Stellenbosch University, School of Public Management and Planning, viewed 15 January 2017, from https://scholar.sun. Management and Planning, viewed 15 January 2017, from https://s
ac.za/bitstream/handle/10019.1/2181/gaffoor_assesing_2008.pdf.

Gay, L.R. \& Airasian, P., 2003, Educational research: Competencies for analysis and application, 7th edn., Prentice-Hall, Upper Saddle River, NJ.

Hasanali, F., 2002, Critical success factors of knowledge management, viewed 25 May 2017, from http://providersedge.com/docs/km_articles/Critical_Success_Factors_ of_KM.pdf.

Hedlund, G. \& Nonaka, I., 1993, 'Models of knowledge management in the West and Japan', in P. Lorange, B. Chakravarthy, J. Roos \& A. Van de Ven (eds.), Implementing strategic process: Change learning and co-operation, pp. 117-144, Blackwell, Oxford.

Hourigan, A., 2017, Importance of knowledge management in South Africa, viewed 12 May 2017, from http://tshikululu.org.za/importance-of-knowledgemanagement-in-south-africa/.

Jalaldeen, R., Karim, N.S.A. \& Mohamed, N., 2009, 'Organizational readiness and its contributing factors to adopt knowledge management processes: A conceptual model', Communications of the IBIMA 8(9), 128-136.

Karuoya, L.N. \& Senaji, T.A., 2017, 'Knowledge conversion capability and organizational effectiveness among private Universities in Kenya: A SECI model perspective', International Journal of Innovative Research and Development 6(3), 162-167.

Kermally, S., 2002, Effective knowledge management: $A$ best practice blueprint, John Wiley and Sons, West Sussex.

Khanal, L., 2016, 'Awareness of knowledge management in Nepalese financial institutions', Journal of Advanced Academic Research 3(3), 76-88. https://doi. org/10.3126/jaar.v3i3.16856

Kimani, L.W., 2013, 'Knowledge-management in the public sector: Its role in facilitating the delivery of health infrastructure', Unpublished Dissertation (MIM), University of the Western Cape, Department of Information Systems, Faculty of Economic and Management Sciences, viewed 15 January 2017, from http://hdl. handle.net/11394/4070.

King, W.R., 2009, 'Knowledge management and organizational learning', in W.R. King (ed.), Knowledge management and organizational learning, pp. 3-13, Springer, New York, NY, viewed 01 June 2017, from http://www.uky. edu/ gmswan3/575/KM_and_OL.pdf.

Ling, N.E., Bakar, R. \& Islam, M.A., 2014, 'Awareness of knowledge management among higher learning institutions: A review', Advances in Environmental Biology 8(9), 436-439.

Maude, S.M. \& Ncume, L., 2012, 'Knowledge management in the South African legislative sector', Journal of Public Administration 47(2.1), 579-591.

McEvoy, P.J., Arisha, A. \& Ragab, M., 2015, 'A review of knowledge management in the public sector: A taxonomy', in Proceedings of the 10th edition of the international forum on knowledge asset dynamics, pp. 1-11, Culture, Innovation and Entrepreneurship: Connecting the Knowledge Dots, Bari, June 10-12, 2015.

McEvoy, P.J., Ragab, M.A. \& Arisha, A., 2017, 'Review on the KM applications in public organisations', The Electronic Journal of Knowledge Management 15(1), 37-48.

Memon, S.B., 2015, 'Relationship between organizational culture and knowledge creation process in knowledge-intensive banks', Unpublished Dissertation (PHD), Queen Margaret University, Division of Business, Enterprise and Management, viewed 17 July 2017, from http://etheses.qmu.ac.uk/1827/1/1827.pdf.

Minnaar, F. \& Bekker, K., 2005, Public management in the information age, Van Schaik, Pretoria.

Mohd Zin, I.N. \& Egbu, C., 2010, 'Readiness of organizations to implement a knowledge management strategy: A construction industry overview', in C. Egbu (ed.) Proceedings of the 26th annual ARCOM conference, pp. 789-798, Association of Researchers in Construction Management, Leeds, September 6-8, 2010.

Mphahlele, M.Y., 2010, 'Knowledge management practices in the South African public sector', Unpublished Dissertation (MPhil), Stellenbosch University, Information and Knowledge Management Department, viewed 15 January 2017, from http://hdl.handle.net/10019.1/3023.

Naghavi, M., Dastaviz, A.H. \& Nezakati, H., 2013, 'Relationships among critical success factors of knowledge management and organizational performance', Journal of Applied Sciences 13(5), 755-759. 
Nazim, M. \& Mukherjee, B., 2016, Knowledge management in libraries: Concepts, tools and approaches, Chandos Publishing, Cambridge, MA.

Ncoyini, S. \& Cilliers, L., 2016, 'An evaluation of knowledge sharing in South African local government', in The International Conference on Information Resources Management (Conf-IRM). Proceedings of the 28th Annual Conference of the Southern African Institute of Management Scientists, pp. 573-585, Conf-IRM, Cape Town, May 18-20, 2016.

Nengomasha, C., Mubuyaeta, M. \& Beukes-Amiss, C., 2017, ‘Organisational knowledge management: A case study of the Ministry of Gender Equality and Child Welfare (MGECW) in Namibia', Journal for Studies in Humanities and Social Studies 6(1), 18-40.

Nonaka, I., Reinmoeller, P. \& Senoo, D., 2000, 'Integrated IT systems to capitalize on market knowledge', in T. Nishiguchi (ed.), Knowledge creation: A source of value, pp. 89-109, Macmillan, London.

Nonaka, I. \& Takeuchi, H., 1995, The knowledge-creating company: How Japanese companies create the dynamics of innovation, Oxford University, New York, NY

Nxesi, T.W., 2015, Department of public works strategic plan 2015-2020, viewed 10 March 2017, from http://www.publicworks.gov.za/PDFs/documents/ StrategicPlans/Strategic_Plan_2015_2020_(20-03-2015).pdf.

Omotayo, O.F., 2015, 'Knowledge management as an important tool in organizational management: A review of literature', Library Philosophy and Practice 4(10), 1-23.

Ondari-Okemwa, E.M., 2007, 'An investigation into the practices, procedures, and challenges of knowledge management in government-owned organizations in Kenya', Unpublished Dissertation (PhD), University of Cape Town, Department of Library and Information Studies, Faculty of Humanities, viewed 15 January 2017, from https://open.uct.ac.za/handle/11427/12402.

Organization for Economic Co-operation and Development (OECD), 2003, Conclusions from the results of the survey of knowledge management practices for ministries/ departments/agencies of the central government in OECD member countries, departments/agencies of the central government in OECD member countries,
viewed 25 June 2021, from https://www.oecd.org/officialdocuments/publicdispla viewed 25 June 2021, from https://www.oecd.org/officialdocuments/p
ydocumentpdf/?cote=GOV/PUMA/HRM(2003)2\&docLanguage=En

Pata, K., 2010, 'Obstacles in implementing SECl model in organizations', Tihane WordPress Blog, Weblog Post, 14 January, viewed 03 July 2017, from https:// WordPress Blog, Weblog Post, 14 January, viewed 03 July 2017, from https://
tihane.wordpress.com/2010/01/14/obstacles-in-implementing-seci-model-intihane.wordpronizations/.

Phalatse, H., 2017, Joburg uses knowledge management to lift service delivery, viewed 06 July 2017, from https://joburg.org.za/index.php?option=com content\&view= article\&id $=11747 \&$ catid $=88 \&$ Itemid $=266$.

Potgieter, A., Dube, T. \& Rensleigh, C., 2013, 'Knowledge management awareness in a research and development facility: Investigating employee perceptions', South African Journal of Information Management 15(2), 1-6. https://doi.org/10.4102/ sajim.v15i2.592

Ramohlale, M.P., 2014, 'Knowledge management practices at the Department of Defence in South Africa', Unpublished Dissertation (MIS), University of South Africa, Information Science, viewed 15 January 2017, from http://uir.unisa.ac.za/bitstream/ handle/10500/14618/dissertation_ramohlale_mp.pdf?sequence=1\&isAllowed=y.
Semertzaki, E., 2018, 'Knowledge management skills applicable to information management - Information management skills applicable to knowledge management in an organization', in J.M. Matarazzo \& T. Pearlstein (eds.), The management in an organization', in J.M. Matarazzo \& T. Pearlstein (eds.), The
Emerald handbook of modern information management, pp. 571-604, Emerald Emerald handbook of modern
Publishing Limited, Bingley.

Shirazi, A., Mortazavi, S. \& Azad, N.P., 2011, 'Factors affecting employees' readiness for knowledge management', European Journal of Economics, Finance and Administrative Sciences 33, 167-177.

Shockley, W., 2000, 'Planning for knowledge management: How your company can benefit from using the right information at the right time', Quality Progress 33(3), $57-62$.

Smith, K., 2017, Information and knowledge management department: What we do, viewed 06 July 2017, from http://www.capetown.gov.za/Departments/ Information\%20and\%20Knowledge\%20Management\%20Department.

Talisayon, S. (ed.), 2013, Report on the APO research on knowledge management for public-sector productivity, Asian Productivity Organization, Tokyo, viewed 07 May 2021, from http://www.apo-tokyo.org/publications/wp-content/uploads/ sites/5/Knowledge-Management-for-the-Public-Sector-2013.pdf.

Traunmüller, R., 2012, 'Knowledge management in government: New perspectives', in A. Ko, C. Leitner, H. Leitold \& A. Prosser (eds.), Advancing democracy, government and governance, Proceedings of the Joint International Conference on Electronic Government and the Information Systems Perspective, and Electronic Democracy (EGOVIS/EDEM), pp. 1-9, Springer Berlin Heidelberg, Vienna, September 3-6.

Tubigi, M. \& Alshawi, S., 2012, 'The impact of knowledge management processes on organizational performance', in Proceedings of the 9th European, Mediterranean and Middle Eastern Conference on Information Systems (EMCIS), pp. 747-762, Munich, June 7-8.

University of KwaZulu-Natal research ethics policy (UKZN), 2014, Unpublished, viewed 10 February 2021, from http://research.ukzn.ac.za/PoliciesProcedures.aspx.

Valaei, N. \& Aziz, K.A., 2012, 'Awareness: A study of knowledge management adoption amongst Iranian SMEs', Journal of Organizational Knowledge Management 2012(2012), 1-14

Western Cape Provincial Government, 2013, Knowledge management: Overview viewed 15 March 2017, from https://www.westerncape.gov.za/your_gov/306.

Wiig, K.M., 1993, Knowledge management foundations: Thinking about thinking: How people and organizations create, represent, and use knowledge, vol. 1, Schema Press, Arlington, TX, viewed 21 June 2017, from https://www.researchgate.net/ publication/31672277_Knowledge_Management_Foundations_Thinking_about Thinking_How_People_and_Organizations_Create_Represent_and_Use_ Knowledge_KM_Wiig.

Wilson, C. \& Nawe, J., 2017, 'Knowledge management (KM) practices in institutions of higher learning in Tanzania with reference to Mbeya University of Science and Technology', University of Dar es Salaam Library Journal 12(1), 48-65. 